\title{
Interlanguage Studies in a Cross Cultural Context: The Interlanguage of Spanish Speakers (L1) in an Approach English (L2), German (L3)
}

\author{
Claudia Grümpel \\ University of Alicante \\ grumpel@ua.es
}

\begin{abstract}
This paper focuses on the acquisition of word order in German by adult native speakers of Spanish in an institutional context (longitudinal study) and a contrastive study on children and adolescent acquisition using transversal tests. The theoretical framework is based on generative grammar analysis proposed for verb placement in German and a review of recent acquisition studies. Analyses of verb movement account for an underlying subject-verb-object order for all languages proposed by Zwart $(1993,1997)$ based on parallel works by Kayne (1993, 1994) and Chomsky $(1993,1995)$.
\end{abstract}

\section{Introduction}

This paper hopes to provide more evidence for the German Interlanguage of Spanish speakers with English as L2 and German as L3. Studies have provided evidence on the acquisition of word order in German observing results of a longitudinal corpus focusing on adult native speakers of Spanish in an institutional context (all of the students studied English as L2). A transversal corpus provides data from Spanish children and adolescents with English L2 and German L3.

The longitudinal corpus was the result of analyzing the free oral and written production of Spanish undergraduate students at intermediate and advanced levels during three semesters. The results were contrasted with the production of students whose acquisition took place exclusively in Spain and other students who spent one semester at a German University. In 
addition to this longitudinal corpus, three transversal tests were carried out on our subjects and results were contrasted with those of native German speakers.

The transversal corpus of child and adolescent learners is based on the same three tranversal tests used by Grümpel (2000) and they allow us to provide more evidence regarding these hypotheses. The transversal corpus carried out by Martínez (2005) stems from children and adolescents from 9 to 16 years old. Some of these children are native speakers of basque. The interlanguage of these should also provide more evidence for the "Initial Syntax Hypothesis of Platzack" (1996).

\section{Theoretical framework}

The theoretical framework of this study is based on the generative grammar analysis proposed for verb placement in German and a review of recent acquisition studies. Early word order studies in this framework of German were based on an underlying subject-object-verb order initiated by Koster (1975) and Den Besten (1977). Recent analyses of verb movement account for an underlying subject-verb-object order for all languages as proposed by Zwart (1993, 1997), based on parallel works by Kayne $(1993,1994)$ and Chomsky $(1993,1995)$.

In this study, I adopt the proposal made by Zwart, Kayne and Chomsky, and I analyze the production of the subjects based on an underlying SVO order. The superficial word order we find in the oral and written language are considered to be a result of verb and object movement.

In the Minimalist Program $(1993,1995)$ the parametrical variation is localized as in former analyses in functional categories. In addition, features are introduced and the directionality parameter is revised since all movements are made to the left (Kayne, 1994). Parameterization exists in the form of features [+/-].

More concretely, in this SVO approach, overt movement needs strong verbal features in $\mathrm{AgrS}$, but in the case of German the absence of verb movement in embedded clauses implies that these features are not strong. Therefore, Zwart (1993) assumes that strong nominal features ( $\mathrm{N}$-features include person and number) trigger movement from $\mathrm{V}$ to AgrS where they are lexicalized as subject- initial main clauses (1a.).

Embedded clauses (1b.) introduced by a complementizer contain lexical and categorical features (LC-features). In Zwart's analysis, the formal features of the verb rise in all clauses to AgrS and are attracted by the complementizer (COMP). The verb cannot be lexicalized in COMP, as the complementizer already contains LC-features and is achieved with the help of the formal features of the verb. The result is the lexicalization of the complementizer and the finite verb remains in situ which gives us a superficial COMP SOV order.

Finally, there is the case of non-subject-initial clauses where COMP is projected with a lexically empty complementizer (1c). In this case as well, the formal features of the verb rise first on to AgrS and go on to COMP; nevertheless, there is no complementizer and there are no LC-features either. Therefore, the F-features of the verb need the LC-features and oblige them to rise as a Last Resource operation. The result is lexicalization of $\mathrm{V}$ in $\mathrm{C}$ which gives us a superficial VSO order. 


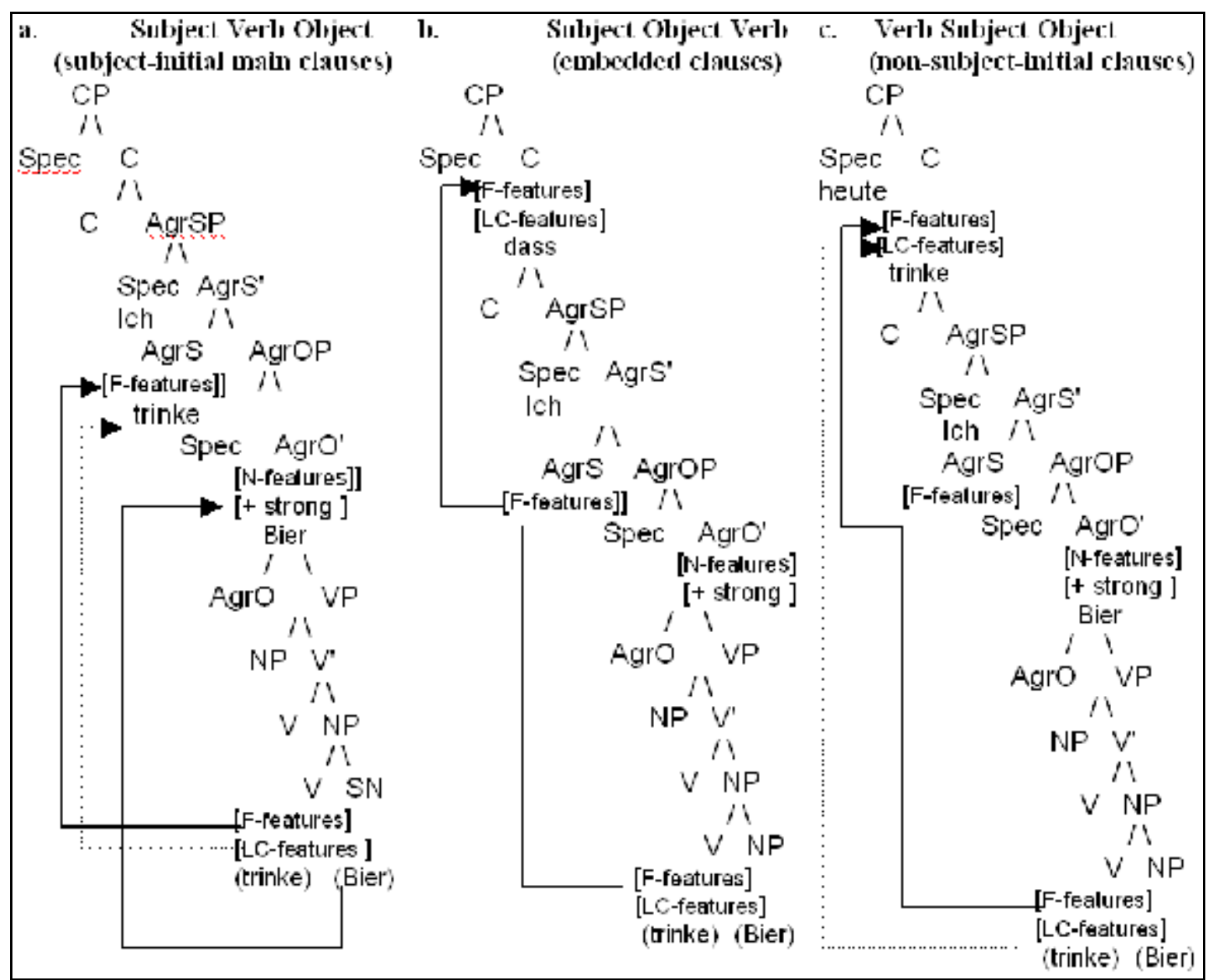

Figure 1. SVO approach.

This approach is based on the assumption made by Halle and Marantz (1993), Chomsky (1995) and Zwart $(1993,1995)$ that lexical elements are bundles of features which contain formal features (F-features) and lexical categorical features (LC-features). From this point of view movement is a combination of F-movement and LC-movement. Movement to check features is always F-movement, while LC-movement is a "last resort movement" to create a morphosyntactic complex which contains F and LC-features.

What I wish to analyze is whether these movements are present in the German interlanguage and especially whether LC-features are interpreted correctly by our subjects. In the case of non-subject-initial main clauses, we pay special attention to the LC-movement as last resort movement.

Platzack (1996) proposes the Initial Hypothesis of Syntax (HIS) assuming a SVO order as initial state for Language Acquisition. For Platzack, marked values in the initial state of language do not exist. This means that all values are initially weak for First and Second Language Acquisition. In this way, language acquisition could be seen as a gradual process from the IHS state towards values of the language to be acquired.

We also have to mention the pioneering ZISA project (Zweitspracherwerb italienischer, 
portugiesischer und spanischer Arbeiter) of Meisel, Clahsen and Pienemann (1981) and related studies. We remember that this study focused on Italian, Portuguese and Spanish workers and their acquisition of German in a longitudinal study. The results of this research were the well known developmental sequence on the acquisition of German word order:

Figure 2. Developmental sequence on the acquisition of German word order

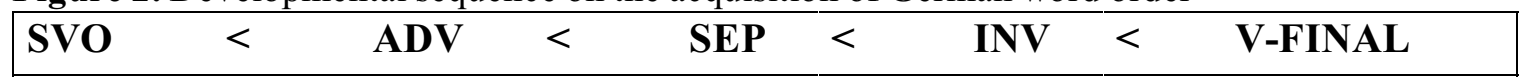

(Clahsen, 1980; Pienemann, 1980, 1981; Meisel, Clahsen y Pienemann, 1981; Clahsen,Meisel y Pienemann, 1983)

The subjects of ZISA started out using a canonical SVO order. In the second stage, they used adverbs in a topicalized position, but without respecting subject inversion. In the third stage of developmental sequence, verbal material was separated (separate verbs, perfect, modals). Having achieved this step, subjects start to invert correctly (XVSO). Mastering of previous structures enables subjects to apply final verbs in embedded sentences.

A lot of research has been done since and a large number of manuals apply this sequence; hence, acquisition studies in an institutional context are marked by these learning steps. The proposal of this study is not to refute former findings, but to investigate the distribution of deficient structures at an intermediate level and the influence of L1 and Universal Grammar at this stage.

\section{Working Hypothesis}

Adopting the theoretical framework of Chomsky, Kayne and Zwart we pretend to answer the following statements for L2 acquisition (Grümpel, 2000):

Do second language learners acquire verb movement [+/-] and object movement $[+]$ systematically or is movement in Interlanguage Grammars just optional? Does natural and instruction input lead student to review strong or weak values in their L2- lexis?

Do lexical categories inherent to all complementizers in German trigger their lexicalization in $\mathrm{C}$ and therefore need no verb movement? Is there a sensibility for LC-features in an explicit complementizer in L2 acquisition?

Do L2-learners show less sensibility regarding the following abstract movements? Topicalization projects $\mathrm{C}$ without lexical features, therefore $\mathrm{C}$ needs the LC-features of the verb for work in $\mathrm{C}$.

Do L2-learners overgeneralize verb final patterns once they are incorporated into their Interlanguage Grammar?

\section{Longitudinal study (adult university students)}

\subsection{The corpus}

The acquisition data of this study comprises 8 Spanish undergraduate students from a Spanish University between 19 and 25 years old. All subjects started German classes at the same 
University in Spain without any previous knowledge of the language. At the end of their 2nd year, students were administered a level test with scores ranging between middle and high intermediate levels. I decided to divide the research data into three groups, as we can see in Figure 3.

Figure 3. Experimental Groups (Grümpel, 2000, 2009)

Experimental Group I:

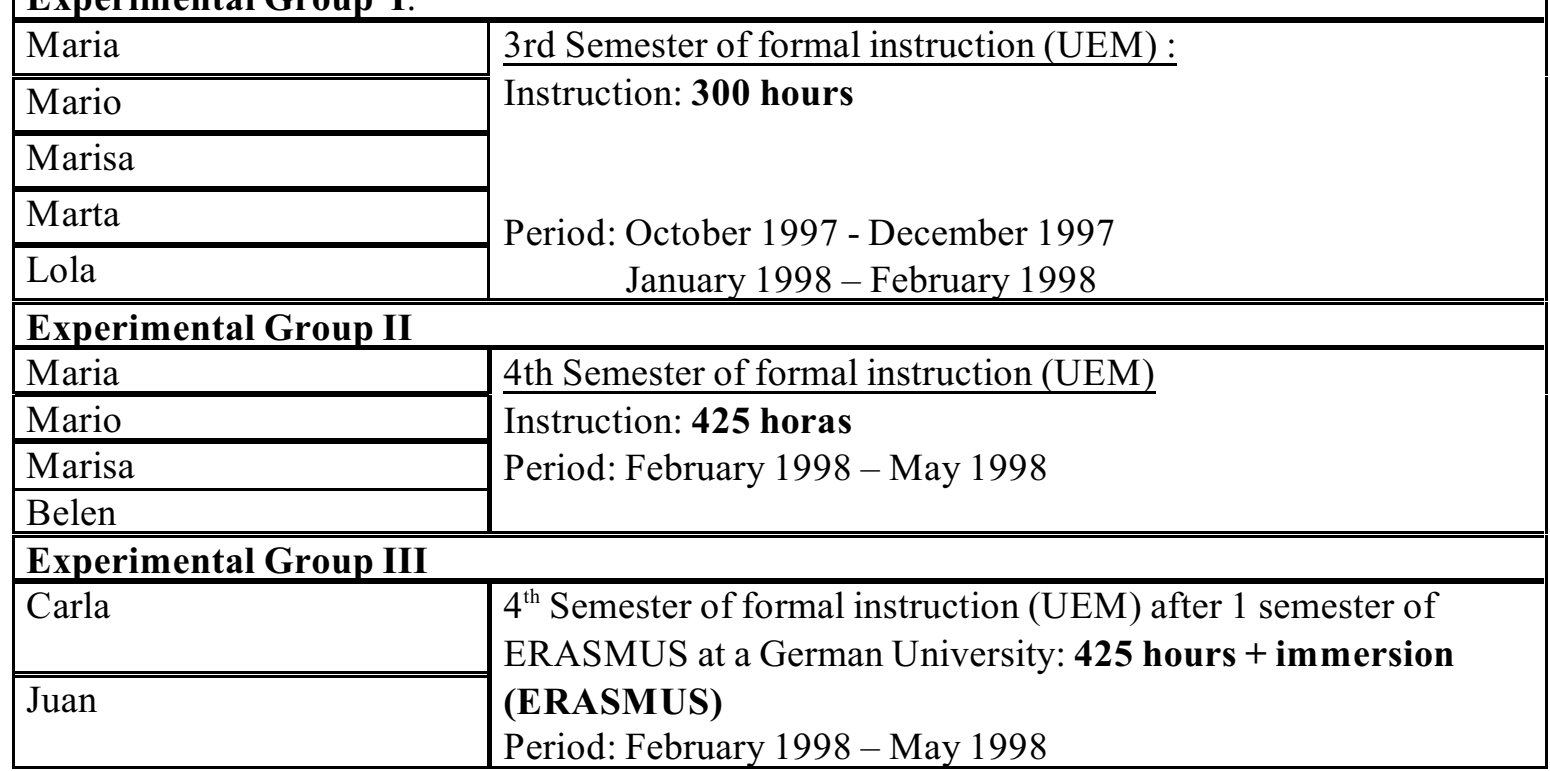

*All names of subjects are pseudonyms

As we can see in Figure 3, the subjects received intensive instruction during their first year at university (Spanish L1, English L2, German L3). The longitudinal data stems from their second year of university. Special attention was paid to the third group who spent one semester at a German university as exchange students following the same program. Data from Group I was taken after 300 hours of instruction input. Group II started out with 425 hours of instruction and finished its 2nd year with 565 hours of formal instruction.

In Figure 4 we see that our subjects have been followed longitudinally throughout the acquisition of German as a third language. At the end of this empirical study they were also underwent cross-linguistic studies via written and oral tests regarding SVO, XVSO and SOV structures.

Figure 4. Corpus data

\begin{tabular}{|l|l|}
\hline Longitudinal Study & -written competence \\
\hline Cross-linguistic data (transversal) & $\begin{array}{l}\text { - oral and written multiply choice/plus } \\
\text { justification }\end{array}$ \\
\hline \hline Cross-linguistic data & - translation test \\
\hline
\end{tabular}

The data for the longitudinal study was collected during periods from one to two weeks in the classroom after having given lexical items regarding the topic of the essay. In each group, we collected samples from our students over a period of one to two weeks. We 
analyzed a total of 1966 samples of sentences produced by our subjects.

In the transversal test, students were given a grammatical judgment exam consisting of 90 sentences. In the oral test, students listened to sentences read aloud by a native speaker and then had to decide whether each sentence was grammatically correct or not.

\subsection{Results and discussion}

Taking into account the data results illustrated in Figure 5, there is evidence that the students of this study showed the following hierarchy on difficulty:

XVSO > SOV > SVO

Figure 5: Non native forms for each empirical group and structures

\begin{tabular}{|l|l|l|l|}
\hline & Group I & Group II & Group III \\
\hline XVSO & $40,32 \%(75 / 186)$ & $25,96(27 / 104)$ & $11,11 \%(12 / 108)$ \\
\hline SOV & $16,09 \%(44 / 274)$ & $12,61(14 / 111)$ & $8,61 \%(13 / 151)$ \\
\hline \hline SVO & $7,23 \%(26 / 336)$ & $6,09 \%(14 / 230)$ & $3,43(6 / 175)$ \\
\hline
\end{tabular}

The first group, which was the least advanced, showed that subject initial main clauses (SVO) were used preferentially at the beginning and were quite close to native level. Given that this was the most used structure at this stage compared with marked structures such as SOV and XVSO, we see that this unmarked form is used with preference in their L1 (Spanish) and their L2 (English). As they went on in their acquisition process, our students used more and more complementizers and incorporated object movement $[+]$ paired with absence of verb movement [-]. Nevertheless movements were optional in this group .

On the other hand, the data showed that the German embedded structure SOV was growing more robust in Groups II and III, as non-native forms in SOV dropped in Group II from $16,09 \%$ to $12,61 \%$ and in Group III to $8,6 \%$. This data suggests that [+/- verb movement] and [+object movement] is incorporated gradually according to instruction and input data. This process is not lineal, as is shown in Figures 6 and 7.

Figure 6. Non native forms in embedded clauses (SOV) per group and data collection.

\begin{tabular}{|l|l|l|l|l|l|l|l|l|l|l|}
\hline Period & 1 & 2 & 3 & 4 & 5 & 6 & 7 & 8 & 9 & 10 \\
\hline Group I & $36 \%$ & $30 \%$ & $14 \%$ & $31 \%$ & $9 \%$ & $16,5 \%$ & $11 \%$ & $6 \%$ & $9,5 \%$ & \\
\hline \hline Group II & $11 \%$ & $12,5 \%$ & $0 \%$ & $23 \%$ & $7,5 \%$ & $30 \%$ & $0 \%$ & $15,5 \%$ & $16,5 \%$ & \\
\hline Group III & $16,5 \%$ & $0 \%$ & $5,5 \%$ & $8,5 \%$ & $11 \%$ & $6,5 \%$ & $10 \%$ & $10 \%$ & $7,5 \%$ & $7 \%$ \\
\hline
\end{tabular}

Figure 7. Non native forms in subject initial clauses SVO for group and data collection.

\begin{tabular}{|l|l|l|l|l|l|l|l|l|l|l|}
\hline Period & 1 & 2 & 3 & 4 & 5 & 6 & 7 & 8 & 9 & 10 \\
\hline \hline Group I & $7 \%$ & $2 \%$ & $0 \%$ & $3 \%$ & $22 \%$ & $2,5 \%$ & $3 \%$ & $12 \%$ & $13 \%$ & \\
\hline \hline Group II & $10 \%$ & $0 \%$ & $10,5 \%$ & $0 \%$ & $4 \%$ & $0 \%$ & $5 \%$ & $11,5 \%$ & $9 \%$ & \\
\hline Group III & $7,5 \%$ & $13,5 \%$ & $0 \%$ & $0 \%$ & $0 \%$ & $6 \%$ & $0 \%$ & $0 \%$ & $5 \%$ & $5 \%$ \\
\hline
\end{tabular}


Data suggests that movements appear profusely in the non native grammar, but these movements are not internalized as in the native grammar, since optional movement appears sporadically, which indicates that movements are detected by an active process of meta linguistic analysis.

As far as the second working hypothesis is concerned the role of LC-features inherent to explicit complementizers in German, we suggest that there is a lexical acquisition combined with intuition and an active process detecting the absence of verb movement and object movement. Comparing failures on SOV and XVSO, production data shows that in Group I, $16,06 \%$ non-native structures were found in embedded clauses (SOV), compared to $40,32 \%$ found in non subject initial main clauses (XVSO). In Group II 12,96\% SOV errors were found, compared to $25,96 \%$ found in inversion structures (XVSO). Data of group III is less evident, but there were still $8,61 \%$ failures on SOV compared to $11,11 \%$ on XVSO structures.

Having suggested for explicit complementizers with inherent LC-features that a lexical element helps to detect object movement and absence of verb moment, the answer to our third working hypothesis, taking into account our acquisition data, shows that there is evidence that the abstract movement required for non subject initial main clauses (XVSO) is harder to detect. Topicalization (XVSO) in German projects $\mathrm{C}$ without complementizer, therefore the verb needs LC-features of the verb in order to be 'spelled out' in C position. The data exposes the fact that this abstract movement is difficult to detect for L2-learners.

The hypothesis regarding the generalization of verb final structures in non-embedded clauses, was confirmed by the data. All the subjects of this study showed SOV generalization in their data. This phenomenon was most evident in the first group, as we can observe in Figure 8 .

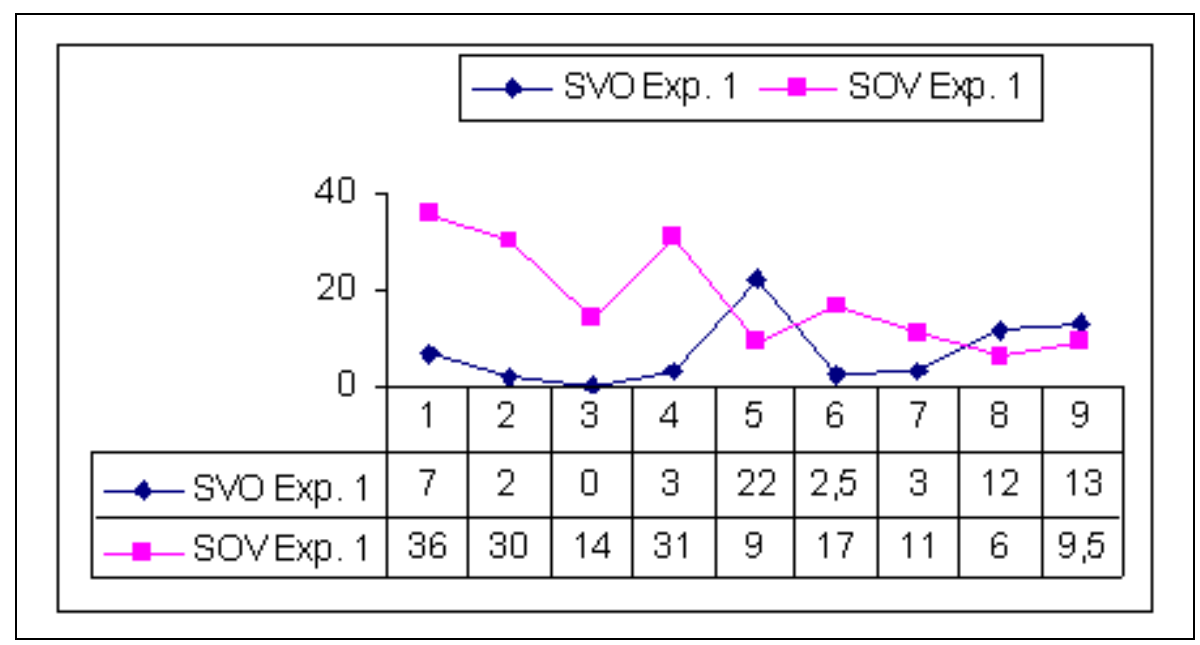

Figure 8. Generalization of SOV in SVO (Group I).

We can observe in data collection number 5 that Group I greatly reduces non native forms in SOV accompanied with a drastic rise of failures on SVO introducing object movement with final verb patterns. As we can see in 6 to 9, non native forms on SOV, once dropped, are maintained on a lower level paired with a generalization of verb final structures in subject 
initial main clauses. This pattern is repeated in Group II and III although it is less evident, as we can see in Figures 9 and 10.

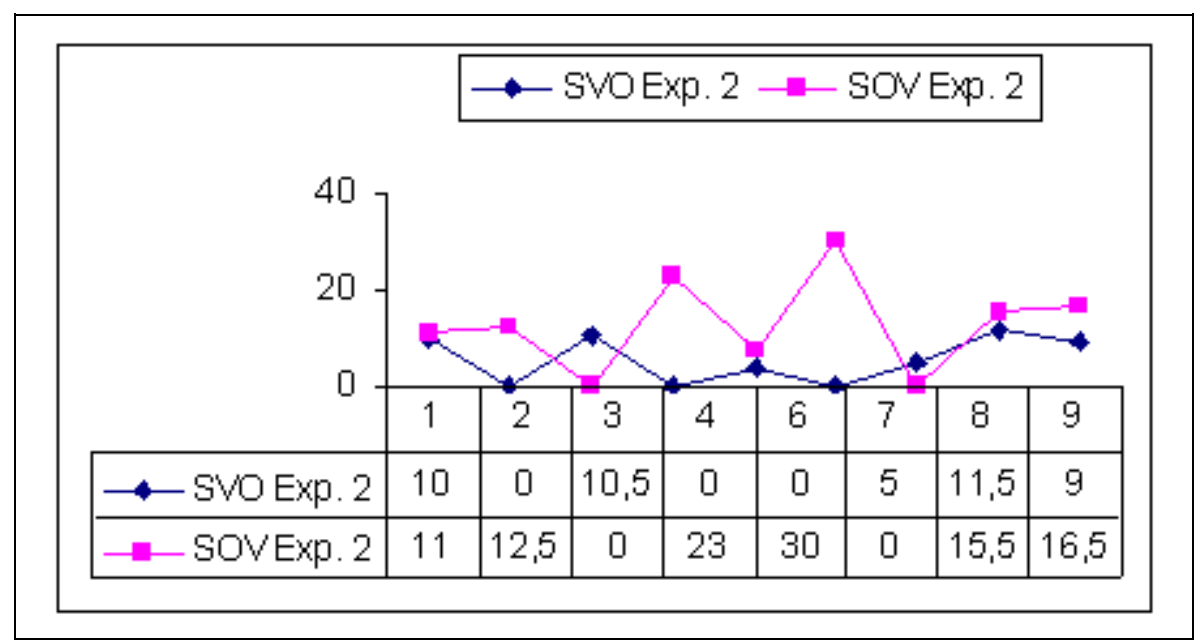

Figure 9. Generalization of SOV in SVO (Group II).

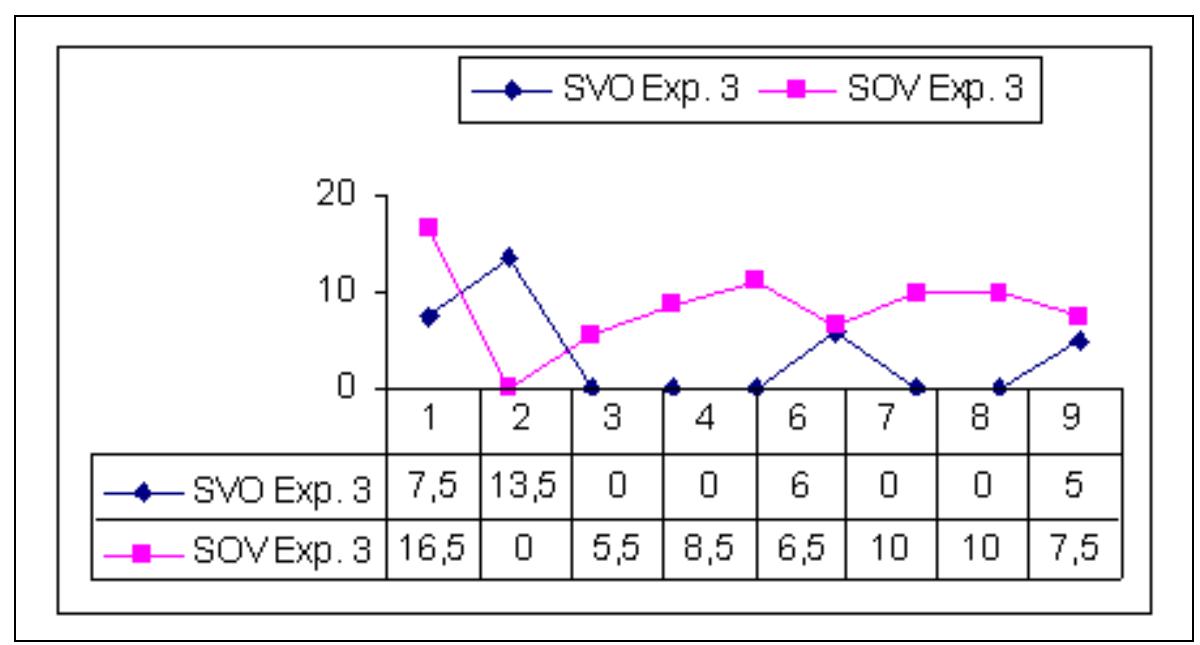

Figure 10. Generalization of SOV in SVO (Group III).

\subsection{Transversal corpus (children and adolescents)}

The acquisition data of this study is taken from the transversal tests of children and adolescents from the Basque Community in Spain aged between 9 and 16 years. A transversal test was given to these children and adolescents, consisting of a writing test, an oral test and a grammar test. All tests were carried out at the same time at different levels. The data is divided into 7 groups, group I to IV, having received two German lessons a week for 3 to 4 years. 
9.a. Written production- \% correct production

$\begin{array}{llllll} & \text { SOV } & \text { VSO } & \text { SVO } & \text { COORD } & \text { TOTAL } \\ \text { I } & 80 \% & 59,8 \% & 100 \% & 74.1 \% & 74,1 \% \\ \text { II } & 85 \% & 74,8 \% & 92,9 \% & 87,8 \% & 81,4 \% \\ \text { III } & 22,2 \% & 38,3 \% & 91,3 \% & 60,5 \% & 60,4 \% \\ \text { IV } & 41,4 \% & 52,9 \% & 92,9 \% & 75,0 \% & 68,3 \%\end{array}$

The data on free writing skills (9a.) shows that students reveal in their interlanguage a lot of non-native production in SOV-structures. Thus we can see that students produce mostly SVO structures. Verb and Object movement are optional. Pro Drop could also be observed. As with the data of the adult corpus, we find productions with SVO after COMP and VSO after conjunctions which require SVO. So we can see SVO errors with composed tense structures. The hierarchy on difficulty was $\mathrm{SOV}>\mathrm{COORD}>\mathrm{VSO}>\mathrm{SVO}$ for these groups.

9.b. Transversal Grammar Test - \% correct

$\begin{array}{llllll} & \text { SOV } & \text { VSO } & \text { SVO } & \text { COORD } & \text { TOTAL } \\ \text { I } & 68,8 & 68,8 & 81,1 & 62,1 & 69,5 \\ \text { II } & 65,3 & 73,3 & 75,6 & 60,7 & 68,3 \\ \text { III } & 79,4 & 69,3 & 79,9 & 72,3 & 74,6 \\ \text { IV } & 67,9 & 66,0 & 84,3 & 67,3 & 71,0\end{array}$

As we can see in 9.b the data of the transversal Grammar Test reveals the hierarchy on difficulty:

COORD $>$ VSO $>$ SOV $>$ SVO

This hierarchy is identical to the one we see by Grümpel $(2000,2009)$ and different to that of Zisa.

a. Students accept Adv SVO structures with errors.

b. Students accept SVO structures in embedded sentences.

c. Students accept inversion in embedded sentences as correct.

d. Students accept LC-features in conjunctions of coordination.

e. Students accept VSO after the conjunction of coordination.

Group III again confirms the results of Grümpel $(2000,2009)$ and repeats the results of group I

$\mathrm{VSO}>\mathrm{COORD}>\mathrm{SOV}>\mathrm{SVO}$ 
Group IV: Hierarchy of difficulty

$\mathrm{VSO}>\mathrm{COORD}>\mathrm{SOV}>\mathrm{SVO}$

Group IV also repeats the same hierarchy and we observe evidence in all groups that the typology of errors and the hierarchy of difficulty found by Grümpel is confirmed. There is strong evidence in all tests to the hierarchy of difficulty: $\mathrm{SVO}-\mathrm{VSO}-\mathrm{SOV}$ which claims that the acquisition sequence found by Clahsen, Meisel, Pienemann, seems to be different in an institutional context. In the transversal test of children and adult acquisition we observe the following:

a. SOV structures are generalized and there is a transfer to SVO and VSO-structures

b. VSO structures are accepted in coordinated conjunctions and in conjunctions of embedded sentences

c. In Groups III and IV we can observe the same hierarchy on difficulty: $\mathrm{VSO}>\mathrm{COORD}>\mathrm{SOV}>\mathrm{SVO}$

d. Inversion (VSO) is less acceptable than (SOV)

The hypothesis of Zwart is that VSO structures require movement of F-features to COMP, but also the movement of LC-features to the verb. The learner has to project COMP without any lexical help. There is evidence in the Interlanguage of these children that there is no triggering of transfer for projection of COMP. Lexical features induce this projection only by lexical items.

\begin{tabular}{llllll} 
9.c. & \multicolumn{6}{l}{ Transversal data from the Translation-Test } \\
& SOV & VSO & SVO & COORD & TOTAL \\
I & $75,6 \%$ & $51,7 \%$ & $59,3 \%$ & $65,2 \%$ & $63,5 \%$ \\
II & $42,9 \%$ & $69,0 \%$ & $64,8 \%$ & $55,0 \%$ & 57,9
\end{tabular}

This test only includes subjects with Basque L1. Students with Spanish L1 are excluded. Group I and II study English as their first foreign language (L2) and German as a third foreign language (L3). The data can be easily compared with the subjects of the adult corpus, since they studied English as L2 and German as L3.

In the translation data there was evidence of the following error typology:

a. Placement errors in adverbs in simple clauses SOV

b. Word placement errors in SVO after adverbs

c. Wrong transfer of LC-features to the conjunction of coordination.

d. SVO order after COMP

e. No inversion after embedded clauses

f. Hierarchy on difficulty: VSO-COORD-SOV-SVO

Even this group with Basque L1 shows more difficulty with VSO than with SOV. The placement errors in adverbs (a) could be explained by the English L2 which allows a 
placement between Subject and Auxiliary Verb. Evidence for Basque transfer will not be studied in this paper.

\section{Conclusions}

We have seen that the new data provided by Martínez (2005) shows evidence and the results and hypotheses made by Grümpel (2000) can be confirmed. There is evidence both in the child and adolescent data that the hierarchy of difficulty pointed out by Grümpel is SVO $\mathrm{SOV}-\mathrm{VSO}$. This means that the acquisition sequence in an institutional context seems to be different than the one shown by Clahsen, Meisel, Pienemann in ZISA.

Considering this hypothesis, it was to be expected that object [+] and verb [+/-] movement in $\mathrm{L} 2$ acquisition by adults can only be achieved as optional movements, this has also ben shown by the child and adolescent corpus.

For the LC-feature, I propose a lexical acquisition which also includes intuition for verb movement, this means, following Zwart, there is evidence for sensibilization to abstract movements. There is movement, but optional movement. In both studies there was evidence for sensibilization to LC-features and verb movement. The results show evidence which supports the sensibilization of abstract movement, but in an optional way.

Learners obviously overgeneralize verb final patterns once they are incorporated into their Interlanguage Grammar, as we can see in the following data. (10a)

10.a Overgeneralization of SOV in SVO (Grümpel, 2000)

$\begin{array}{llllllllll}\text { Test } & 1 & 2 & 3 & 4 & 5 & 6 & 7 & 8 & 9 \\ \text { SVO Gruppe I } & 7 \% & 2 \% & 0 & 3 \% & 22 \% & 2,5 \% & 3 \% & 12 \% & 13 \% \\ \text { SOV Gruppe I } & 35 \% & 30 \% & 14 \% & 31 \% & 9 \% & 17 \% & 11 \% & 6 \% & 9,5 \%\end{array}$

An overgeneralization could be observed mainly in the lover levels, Group I. We see that beginning with test 5 , students improve in embedded phrases SOV, but at the same time they produce an overgeneralization and show more errors in simple SVO structures.

Finally, a remark on methodology: transversal studies can not deliver the same evidence as longitudinal studies, because they can not take into account evolution and the non-linear process of interlanguage. Therefore, longitudinal studies should be used first to establish the evidence, with transversal data only being used to confirm the findings.

\section{References}

Beck, M.L. (1998): "L2 Acquisition and obligatory head movement: English-speaking Learners of German and the Local Impairment Hypothesis", Studies in second Language Acquisition, 20, 311-348.

Chomsky, N. (1995): “The Minimalist Program", Cambridge: MIT Press.

Grümpel, C. (2000a). El papel de los principios de la Gramática Universal y de la lengua primera en la adquisición del orden de palabras del alemán por adultos hispanohablantes. Ph.D. Dissertation, Unversity of Complutense, Madrid, I.U. Ortega y Gasset. Madrid. 
. (2000b): "Algunos aspectos morfosintácticos y la variación del orden de palabras en la clase de traducción del español al alemán”, Panorama actual de la Lingüística Aplicada, Tomo II, $p$. $1298-1295$.

. (2000c): “Algunos aspectos teóricos y su aplicación en la clase de intepretación consecutiva (español-alemán-español)”, Simposio Internacional sobre interpretación de conferencias, Universidad de Valladolid., p. 193-200.

- (2000d): El papel de los principios de la Gramática Universal y de la lengua primera en la a dquisición del orden de palabras del alemán por adultos hispanohablantes, Tesis doctoral, Universidad Complutense, I,U. Ortega y Gasset, Madrid.

. (2002): "The Acquisition of German Syntax by Spanish Speaking Advanced Learners of German Based on an Underlying Subject Verb Order", Círculo de Lingüistica Aplicada (CLAC), $11,1-12$.

. (2002b): “Topicalización y Comp en la interlengua alemana”, Cuadernos de Lingüística, $X I, p \cdot 105-112$

. (2008): "Theoretischer und empirischer Vergleich zum deutschen Spracherwerb". Revista de Lingüistica y Lenguas Aplicadas p. 1-13. Spain.

. (2009a): "Die linke und rechte Satzperipherie des Deutschen in Hinblick auf Transferenzfehler im Spracherwerb" Proceedings University Salamanca.

. (2009b): "Merkmalbasierte Analyse: Der Erwerb der Asymmetrie der deutschen Syntax. Proceedings University Sevilla.

. (2009c): La adquisición del alemán en un contexto universitario por hispanohablantes. Collección Interlingua, Comares. Spain..

Kayne, R.S., (1994). The Antisymmetry of Syntax, MIT Press, Cambridge.

Koster, J. (1975). Dutch as an SOV Language. Linguistic Analysis 1, pp. 111-136.

Liceras, J.M. y Díaz, L. (1998). On the nature of the relationship between morpohology and syntax: f-features and null/overt pronouns in the Spanish interlanguage. In Beck, M.,L., (ed.), Morphology and its interfaces in second-language knowledge. John Benjamins, Amsterdam, pp. 307-338.

Martínez Adrián, M. (2005): El papel de la segunda lengua en la adquisicón del orden de palabras del alemán como tercera lengua. Universidad del País Vasco, Tesis Doctoral.

Meisel, J., H. Clahsen y M. Pienemann (1981). On determining developmental stages in natural second langauge acquisition. Studies in Second Language Acquisition 3, pp.109-135.

Platzack, C. (1996): The Initial Hypothesis of Syntax: A Minimalist Perspective on Language Acquisition and Attrition. Clahsen H., Generative Perspectives on Language Acquisition. Amsterdam: John Benjamins, 396-414.

Zwart, J.W. (1993a): Clues from Dialect Syntax: Complementizer Agreement. In W. Abraham y J. Bayer, Dialektsyntax. Special issue nr. 5. Linguistische Berichte, 246-270.

. (1993b): Dutch Syntax. A Minimalist Approach. Ph.d. dissertation, University of Groningen.

. (1997): Dutch Syntax: A Minimalist Approach, Kluwer, Dordrecht. 